\title{
Systematic review and website presentation of validated dietary assessment tools
}

\author{
M. Warthon-Medina ${ }^{1}$, J. Hooson ${ }^{1}$, N. Hancock ${ }^{1}$, L.E. Gibson ${ }^{1}$, L.A. Bush ${ }^{1}$, J. Hutchinson ${ }^{1}$, \\ D.C. Greenwood ${ }^{2}$, S. Robinson ${ }^{3}$, V.J. Burley ${ }^{1}$, M. Roe ${ }^{4}$, T. Steer ${ }^{5}$, P.A. Wark ${ }^{6}$, J.E. Cade ${ }^{1}$ \\ and on behalf of the DIET@NET Consortium \\ ${ }^{1}$ Nutritional Epidemiology Group, University of Leeds, Leeds, LS2 9JT, UK, ${ }^{2}$ Division of Biostatistics, University of \\ Leeds, Leeds, LS2 9JT, UK, ${ }^{3}$ MRC Lifecourse Epidemiology Unit, University of Southampton, Southampton SO16 \\ $6 Y D, U K,{ }^{4}$ Quadram Institute Bioscience, Norwich, NR4 7UA, UK, ${ }^{5}$ MRC Elsie Widdowson Laboratory, Cambridge, \\ CBI 9NL, UK and ${ }^{6}$ Centre for Innovative Research Across the Life Course (CIRAL), Faculty of Health and Life \\ Sciences, Coventry University, Coventry CVI 5FB, UK.
}

Accurately measuring diet is critical in understanding the role diet plays on health outcomes, to do this it is important to validate dietary intake methods. However, measuring diet accurately is challenging, therefore it is important to validate dietary intake methods. The DIETary Assessment Tools NETwork (DIET@NET) project aims to provide a central resource where researchers can identify, compare and access appropriate dietary assessment tools (DATs), through the Nutritools website ${ }^{(1)}$ (www.nutritools.org). The purpose of this study was to identify validated DATs for inclusion on the Nutritools website.

A systematic review of systematic reviews ${ }^{(2)}$ of validated DATs that measured some aspect of food or nutrient intake was conducted searching seven electronic databases. DAT papers referenced in the reviews were reviewed to determine eligibility for inclusion into the Nutritools website. Differences in mean intake, Bland-Altman limits of agreement (LOA), correlations and percentage agreements results comparing tools with reference method were extracted or calculated based on the published data. From the 51 systematic reviews identified, 63 DATs validated in the UK were included on the Nutritools website, of these, 2 were validated in multiple countries and are classed as worldwide, and the majority were Food Frequency Questionnaires (FFQs). 50 DATs were validated in adults/ elderly and 16 were validated in children/adolescents. Over 1500 non-UK papers were identified, from these 64 international tools were extracted, 53 and 17 of which were validated in adults/elderly and children/adolescents, respectively. The summary plot below, produced by the Nutritools website, is a novel visual method of comparing the mean difference in intakes and LOA between DATs and their comparator. In figure 1 most FFQs overestimated energy intake compared to the reference method in UK adults.
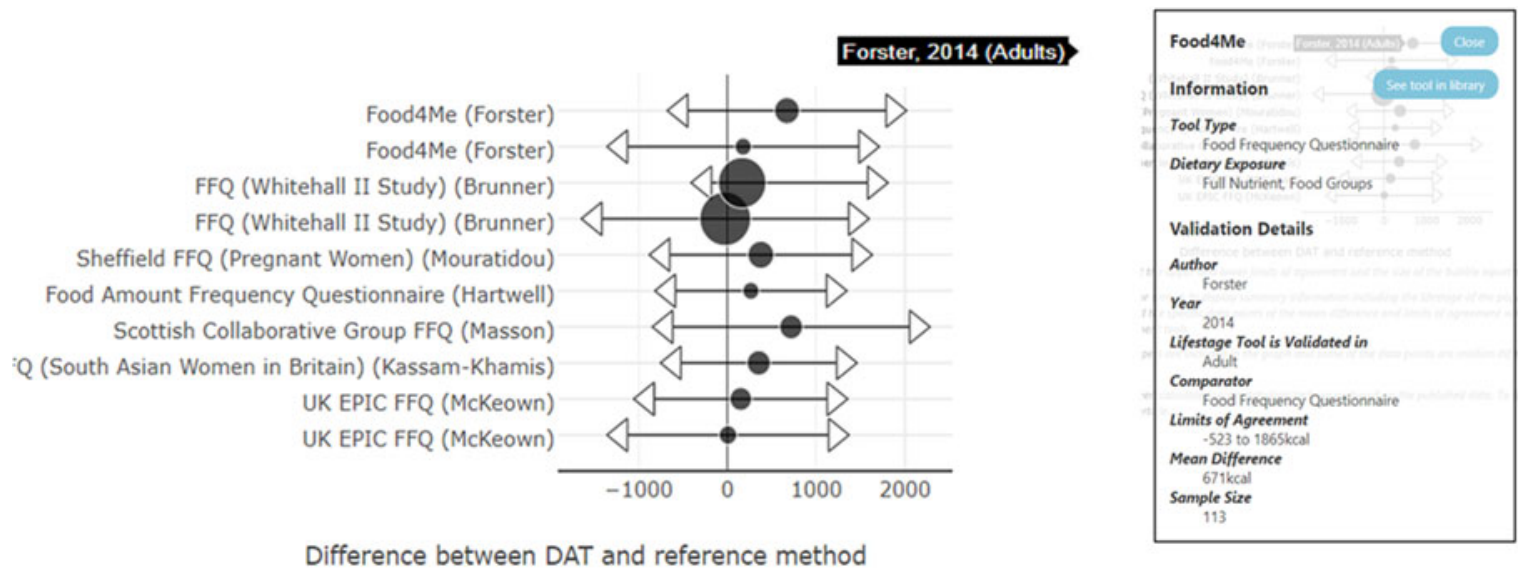

Fig. 1. Comparison of energy intake (kcal) between Food Frequency Questionnaire and the reference method validated in UK adults. Circles positions represent mean differences and circle size represents sample size. Arrow heads denote Limits of Agreement. Hover option detail for each study is illustrated on left for first study.

The review has collated validation data on a variety of UK and international DATs which have been incorporated onto the Nutritools website, an invaluable resource for comparing and selecting the most appropriate DAT.

This project was funded by the UK Medical Research Council [Grant number MR/L02019X/1].

1. Warthon-Medina M, Hooson J, Hancock N et al. (2017). The Lancet 390, pS94.

2. Hooson J, Hancock N, Greenwood DC et al. (2016). Proc Nutr Soc 75(OCE3). 